\title{
Os Professores Podem Fazer Mapas Conceituais? Sim, Eles Devem!
}

\section{Should Teachers Make Concept Maps? Yes, They Must!}

\author{
Paulo Rogério Miranda Correia ${ }^{1 *}$, Raíssa dos Santos Ballego ${ }^{2}$, Thalita de Souza Nascimento ${ }^{2}$ \\ 'Escola de Artes, Ciências e Humanidades da Universidade de São Paulo \\ ${ }^{2}$ Programa de Pós-Graduação Interunidades em Ensino de Ciências da Universidade de São Paulo \\ * Autor para correspondência: prmc@usp.br
}

\section{RESUMO}

\begin{abstract}
A busca por novas formas de ensinar e aprender tem colocado os mapas conceituais em evidência, como forma de representar e compartilhar o conhecimento. Entretanto, o tempo requerido para treinar os alunos na técnica de mapeamento conceitual e avaliar os mapas produzidos por eles é grande demais quando se considera a rotina profissional da maioria dos professores. Uma forma de superar esses obstáculos é colocar o professor na condição de mapeador, criando e usando os seus próprios mapas conceituais durante as aulas. Este artigo apresenta quatro diferentes atividades que podem ser elaboradas a partir de um único mapa conceitual feito pelo especialista: a visualização sistêmica dos conteúdos, a elaboração de proposições a partir de um mapa conceitual parcialmente desenvolvido, a verificação do engajamento dos alunos com os materiais de estudo e a identificação de erros no mapa conceitual. As atividades descritas são rápidas e facilmente adaptáveis pelos leitores interessados em fazer uso frequente dos mapas conceituais. A exposição regular dos alunos aos mapas feitos pelo professor pode ser o primeiro passo para que eles se tornem futuros mapeadores.
\end{abstract}

Palavras-Chave: Mapas Conceituais; Organizador Prévio; Avaliação da Aprendizagem; Atividades de Ensino.

\begin{abstract}
The search for new ways of teaching and learning has placed concept maps in evidence as a way of representing and sharing the knowledge. However, the time needed to train students in the concept mapping technique and to evaluate the maps produced by them is too long considering the professional routine of most teachers. One way to overcome these obstacles is to place the teacher in the position of map maker by creating and using his concept maps in the classroom. This article presents four different activities that can be elaborated from a single concept map made by the expert: the systemic visualization of the contents, the elaboration of propositions from a partially developed concept map, the verification of the students' engagement with the study materials and the identification of errors in the concept map. The activities described are fast and easily adaptable for readers interested in using concept maps frequently. Regular student exposure to teacher-made maps may be their first step to become future mappers.
\end{abstract}

Keywords: Concept Maps; Advance Organizers; Learning Assessment; Teaching Activities.

\section{Introdução}

O interesse de professores e alunos pelos mapas conceituais cresceu nos últimos anos, visto que eles são formas visuais de representar o conhecimento. Eles têm sido utilizados para avaliar a aprendizagem, organizar conteúdos de disciplinas e facilitar o processo colaborativo, seja entre alunos ou entre professor e aluno (e.g., MOREIRA, 2010; NOVAK
\& CAÑAS, 2010). Ver o que os alunos sabem, a partir dos mapas conceituais, permite ao professor oferecer devolutivas precisas e constantes ao longo do processo de ensino-aprendizagem. Como consequência, a promoção da aprendizagem profunda, da meta-aprendizagem e da aprendizagem por toda a vida aumenta consideravelmente. $\mathrm{O}$ artigo "Por que Vale a Pena Usar Mapas Conceituais no Ensino 
Superior?" (CORREIA et al., 2016), publicado na primeira edição da Grad+, explica com maior detalhamento os impactos do mapeamento conceitual sobre o processo de aprendizagem.

NaTabela 1 exemplificamos as diferentes formas da utilização dos mapas conceituais no Ensino Superior, a partir dos trabalhos publicados até o momento na Grad+. Vale a pena destacar a diversidade de áreas de conhecimento desses trabalhos, confirmando que o mapeamento conceitual pode ser aplicado em qualquer disciplina acadêmica (NOVAK \& CAÑAS, 2010). O uso de mapas conceituais para comunicar resultados de pesquisas educacionais é menos explorado do que a sua utilização com alunos. Porém, há vários trabalhos internacionais que mostram formas inovadoras de empregar os mapas como ferramentas de pesquisa (e.g., CONCEIÇÃO, SAMUEL \& BINIECKI, 2017; KINCHIN, STREATFIELD \& HAY, 2010; SCHWENDIMANN, 2015). Dois trabalhos publicados na Grad+ exploram a técnica de mapeamento conceitual para representar os argumentos (CORREIA et al., 2016) e os resultados de pesquisas (RIBEIRO \& VIANA, 2018).

A comparação entre mapas conceituais e instrumentos tradicionais para a avaliação da aprendizagem foi feita por Silva Junior et al. (2017). Representar a articulação entre teoria/prática (MELO, 2018) e disciplinas afins (COOPER-CAPETINI et al., 2017; DIAS et al., 2017) tem sido uma demanda respondida também com mapas conceituais. Nesses casos, os alunos elaboram mapas que são analisados pelo professor e/ou pesquisador(es). Curiosamente, só o trabalho de Dias et al. (op. cit.) apresenta mapas elaborados por alunos (Tabela 1). Uma possível explicação para esse fato são os obstáculos práticos que os professores encontram para incluir o mapeamento conceitual na sua rotina docente. Além de planejar como e quando os mapas serão utilizados em sala de aula, o professor precisa encontrar tempo para:

- treinar os alunos nessa técnica de representação do conhecimento, e

- avaliar os mapas elaborados pelos alunos para fornecer devolutivas apropriadas para cada caso.

Esses obstáculos de ordem prática têm dificultado a disseminação dos mapas conceituais, mesmo que o professor esteja convencido dos seus benefícios. Nosso grupo de pesquisa vem buscando formas de superar essas barreiras (CORREIA, CABRAL \& AGUIAR, 2016), e foi possível identificar outras atividades com menor impacto sobre a rotina do professor. Elas mudam os papéis que alunos (elaboradores dos mapas) e professores (avaliadores dos mapas) frequentemente desempenham. Por que os professores não atuam como mapeadores, criando mapas conceituais a serem utilizados em sala de aula?

\section{O professor como mapeador}

McClure, Sonak e Suen (1999) publicaram um trabalho relevante para discutir aspectos relacionados à praticidade operacional que dificulta o uso do mapeamento conceitual nas condições usuais de trabalho dos professores (aulas em múltiplas turmas, dezenas de alunos por sala e pouco tempo disponível para desenvolver atividades com mapas durante as aulas). Reconhecendo essas dificuldades, o nosso grupo de pesquisa passou a desenvolver atividades utilizando mapas conceituais feitos pelo próprio professor. A Tabela 2 compara a praticidade de tarefas que usam mapas conceituais, destacando a maior facilidade de implementação de atividades quando o professor atua como mapeador.

Os mapas conceituais dos alunos precisam revelar com clareza as relações conceituais que eles construíram durante o período de estudo. Caso contrário, sua utilização como instrumento de avaliação fica comprometida. Por exemplo, ao ler um mapa sem termos de ligação apropriados, o professor sempre se depara com o seguinte dilema: esse mapa está ruim porque o aluno não compreendeu o conteúdo, ou porque ele não consegue construir mapas conceituais adequadamente? A busca por uma resposta exige que o professor trabalhe com os seus alunos, preparando-os para elaborar bons mapas conceituais. Nesse cenário, os mapas insatisfatórios podem ser relacionados com a má compreensão dos conteúdos da disciplina, pois as dificuldades com a técnica de mapeamento conceitual foram minimizadas durante o treinamento. 


\begin{tabular}{|c|c|c|c|c|}
\hline $\begin{array}{l}\text { Área de } \\
\text { conhecimento }\end{array}$ & $\begin{array}{l}\text { Objetivos pretendidos } \\
\text { ao utilizar mapas } \\
\text { conceituais }\end{array}$ & $\begin{array}{l}\text { Quais foram } \\
\text { os principais } \\
\text { resultados? }\end{array}$ & $\begin{array}{l}\text { Há mapas no } \\
\text { trabalho? }\end{array}$ & Referência \\
\hline $\begin{array}{l}\text { Educação } \\
\text { no ensino } \\
\text { superior }\end{array}$ & $\begin{array}{l}\text { Diferenciar os mapas } \\
\text { conceituais dos mapas } \\
\text { mentais e representar } \\
\text { estruturas conceituais } \\
\text { (radial, linear e rede). }\end{array}$ & $\begin{array}{l}\text { Os mapas conceituais } \\
\text { foram elaborados } \\
\text { pelos pesquisadores } \\
\text { para representar parte } \\
\text { da argumentação do } \\
\text { artigo. }\end{array}$ & $\begin{array}{l}\text { Sim. Eles fo- } \\
\text { ram elabo- } \\
\text { rados pelos } \\
\text { pesquisadores. }\end{array}$ & $\begin{array}{l}\text { CORREIA et } \\
\text { al., } 2016\end{array}$ \\
\hline $\begin{array}{l}\text { Engenharia de } \\
\text { transportes }\end{array}$ & $\begin{array}{l}\text { Comparar duas téc- } \\
\text { nicas diferentes para } \\
\text { avaliar o processo de } \\
\text { ensino-aprendizagem } \\
\text { (provas/testes } x \text { mapas } \\
\text { conceituais). }\end{array}$ & $\begin{array}{l}\text { A avaliação tornou-se } \\
\text { mais abrangente, } \\
\text { contemplando o do- } \\
\text { mínio dos conceitos e } \\
\text { das relações concei- } \\
\text { tuais sobre o tema de } \\
\text { estudo. }\end{array}$ & Não. & $\begin{array}{l}\text { SILVA } \\
\text { JUNIOR et } \\
\text { al., } 2017\end{array}$ \\
\hline $\begin{array}{l}\text { Fisiologia } \\
\text { endócrina }\end{array}$ & $\begin{array}{l}\text { Articular os conheci- } \\
\text { mentos prévios, a partir } \\
\text { dos conteúdos de várias } \\
\text { disciplinas (Bioquímica, } \\
\text { Biologia Celular e } \\
\text { Fisiologia). }\end{array}$ & $\begin{array}{l}\text { Apesar de citar o } \\
\text { potencial dos mapas } \\
\text { conceituais, os auto- } \\
\text { res discutem o efeito } \\
\text { do uso de vídeos para } \\
\text { facilitar a articulação } \\
\text { entre disciplinas. }\end{array}$ & Não. & $\begin{array}{l}\text { COOPER- } \\
\text { CAPETINI et } \\
\text { al., } 2017\end{array}$ \\
\hline $\begin{array}{l}\text { Sociedade } \\
\text { e meio } \\
\text { ambiente }\end{array}$ & $\begin{array}{l}\text { Facilitar a aquisição e a } \\
\text { articulação de conheci- } \\
\text { mentos de forma inter- } \\
\text { disciplinar e complexa. }\end{array}$ & $\begin{array}{l}\text { Os alunos foram pro- } \\
\text { tagonistas na constru- } \\
\text { ção ativa do conheci- } \\
\text { mento, demonstrando } \\
\text { maior interesse e } \\
\text { engajamento pelos } \\
\text { conteúdos. }\end{array}$ & $\begin{array}{l}\text { Sim. Eles foram } \\
\text { elaborados por } \\
\text { um grupo de } \\
\text { alunos. }\end{array}$ & $\begin{array}{l}\text { DIAS et al., } \\
2017\end{array}$ \\
\hline $\begin{array}{l}\text { Administração } \\
\text { de empresas }\end{array}$ & $\begin{array}{l}\text { Visualizar definições } \\
\text { conceituais e procedi- } \\
\text { mentos operacionais } \\
\text { para subsidiar a estrutu- } \\
\text { ração da aprendizagem } \\
\text { baseada em problemas } \\
\text { (PBL). }\end{array}$ & $\begin{array}{l}\text { Os mapas conceituais } \\
\text { foram elaborados } \\
\text { pelos pesquisadores } \\
\text { para representar parte } \\
\text { dos resultados. }\end{array}$ & $\begin{array}{l}\text { Sim. Eles fo- } \\
\text { ram elabo- } \\
\text { rados pelos } \\
\text { pesquisadores. }\end{array}$ & $\begin{array}{l}\text { RIBEIRO } \\
\& \text { VIANA, } \\
2018\end{array}$ \\
\hline Direito & $\begin{array}{l}\text { Representar os elemen- } \\
\text { tos práticos e teóricos } \\
\text { da solução de um caso, } \\
\text { estudado a partir das } \\
\text { etapas do Arco de } \\
\text { Maguerez. }\end{array}$ & $\begin{array}{l}\text { A dinâmica das aulas } \\
\text { foi alterada e os } \\
\text { alunos atuaram como } \\
\text { protagonistas du- } \\
\text { rante o processo de } \\
\text { aprendizagem. }\end{array}$ & Não. & MELO, 2018 \\
\hline
\end{tabular}

Tabela 1 - Trabalhos envolvendo a técnica de mapeamento conceitual publicados na Grad + . 


\begin{tabular}{|c|c|c|}
\hline \multirow{2}{*}{$\begin{array}{l}\text { Parâmetros } \\
\text { para avaliar a } \\
\text { praticidade }\end{array}$} & \multicolumn{2}{|l|}{ Quem elabora os mapas conceituais? } \\
\hline & Alunos & Professor \\
\hline $\begin{array}{l}\text { Tempo } \\
\text { necessário } \\
\text { para } \\
\text { treinamento } \\
\text { na técnica de } \\
\text { mapeamento }\end{array}$ & $\begin{array}{l}12345 \\
\text { Os mapas só refletem a estrutura } \\
\text { de conhecimento dos alunos se eles } \\
\text { dominarem a técnica de mapeamento. }\end{array}$ & $\begin{array}{l}123(4) \\
\text { Só o professor deve ser treinado } \\
\text { para fazer bons mapas (AGUIAR \& } \\
\text { CORREIA, 2013). Os alunos precisam } \\
\text { saber como se leem os mapas. }\end{array}$ \\
\hline $\begin{array}{l}\text { Tempo } \\
\text { necessário } \\
\text { para elaborar } \\
\text { os mapas } \\
\text { conceituais }\end{array}$ & $\begin{array}{l}1234(5) \\
\text { Preparar bons mapas requer tempo } \\
\text { para selecionar os conceitos que } \\
\text { respondem adequadamente à } \\
\text { pergunta focal, organizá-los, tornar } \\
\text { claras e corretas as proposições } \\
\text { (AGUIAR \& CORREIA, 2013). }\end{array}$ & $\begin{array}{l}123(4) \\
\text { O professor pode preparar seus ma- } \\
\text { pas com antecedência, sem compro- } \\
\text { meter o tempo das aulas. Os alunos } \\
\text { participam das atividades usando } \\
\text { os mapas durante as aulas, com a } \\
\text { mediação do professor. }\end{array}$ \\
\hline $\begin{array}{l}\text { Tempo } \\
\text { necessário } \\
\text { para avaliar o } \\
\text { conhecimento } \\
\text { do aluno }\end{array}$ & $\begin{array}{l}\text { (1) } 345 \\
\text { Cada mapa MC elaborado pelos } \\
\text { alunos tem que ser lido e avaliado } \\
\text { pelo professor através de um processo } \\
\text { comparativo. Não há nenhum gabarito } \\
\text { predefinido para orientar esse processo. }\end{array}$ & $\begin{array}{l}\text { (1)(3)(3) (5) } \\
\text { As atividades criadas a partir do } \\
\text { mapa feito pelo professor permitem } \\
\text { a produção de um gabarito para } \\
\text { orientar a correção. A avaliação } \\
\text { das respostas se torna mais rápida } \\
\text { e fácil. As devolutivas do professor } \\
\text { podem ser discutidas com os alunos } \\
\text { assim que a tarefa se encerra. }\end{array}$ \\
\hline
\end{tabular}

Tabela 2 - Comparação da praticidade das atividades usando mapas conceituais, considerando alunos e professores como mapeadores. O tempo necessário para cada condição foi representado com uma escala entre 1-5, sendo $1=$ pouco tempo e $5=$ muito tempo.

Dois problemas surgem quando reconhecemos a necessidade de incluir o treinamento na rotina das nossas aulas:

1. O professor já é um bom mapeador, com condições de auxiliar alunos iniciantes na técnica de mapeamento conceitual?

2. O professor pode alocar parte do tempo das suas aulas para desenvolver atividades de treinamento?

A imposição da realidade geralmente faz com que ambas as perguntas sejam respondidas de forma negativa, o que dificulta a verificação dos benefícios associados ao uso dos mapas conceituais. Mesmo quando as respostas são positivas, resta ainda um último problema de ordem prática:

3. O professor terá tempo para corrigir cada um dos mapas dos alunos, considerando que não há um gabarito disponível para facilitar esse processo avaliativo?

A avaliação dos mapas conceituais deve ser comparativa, para que o nível de entendimento atingido pelos alunos seja utilizado como uma referência pelo professor. Faz pouco sentido usar um mapa feito pelo professor e compará-lo com o dos alunos. Atividades de elaboração de mapas comportam várias boas respostas e frequentemente nos surpreendemos com um mapa de aluno que supera as nossas expectativas (nesse caso, o aluno deveria receber uma nota maior do que 10?). A riqueza desses mapas se revela durante o processo de leitura comparativa, quando o professor consegue identificar o que foi bem compreendido, o que precisa ser revisado e o que está faltando 
em cada mapa. A devolutiva esperada pelo aluno inclui observações a respeito desses aspectos, mas ela consome um tempo enorme. Novamente a realidade se impõe e, frequentemente, os professores precisam abrir mão dessa devolutiva ideal para sobreviver durante o semestre letivo. A expectativa dos alunos é frustrada porque o comentário do professor não aproveita todo o esforço exigido pela construção do mapa conceitual. Dar "um pontinho extra" para os alunos que fizeram o mapa é a solução possível em muitos casos, e ela desagrada a todos.

Uma alternativa para superar esses obstáculos é colocar o professor no papel de mapeador, ampliando as possibilidades de uso dos mapas conceituais na sala de aula por meio de atividades que começam com o mapa do especialista. Nesse contexto, os alunos podem participar atuando de diferentes formas, sem que eles tenham que ser treinados na técnica de mapeamento conceitual. As seções a seguir descrevem quatro atividades facilmente implementadas em sala de aula, desde que o professor crie o seu próprio mapa conceitual.

\section{Panorama Geral dos Conteúdos}

A Figura 1 apresenta um mapa conceitual elaborado por um professor para representar as principais relações conceituais dos conteúdos trabalhados em quatro aulas sequenciais sobre o universo. Note que a rede proposicional, contendo 23 conceitos e 26 proposições, foi desenvolvida com a finalidade de responder à pergunta focal "O que sabemos sobre o universo após as aulas da disciplina??. O processo de elaboração e revisão do mapa é uma oportunidade para o professor:

- desenvolver uma visão sistêmica sobre os conteúdos dessas aulas,

- identificar quais são os conceitos mais relevantes para a compreensão do tema,

- localizar onde estão os principais obstáculos de aprendizagem a serem superados pelos alunos, e

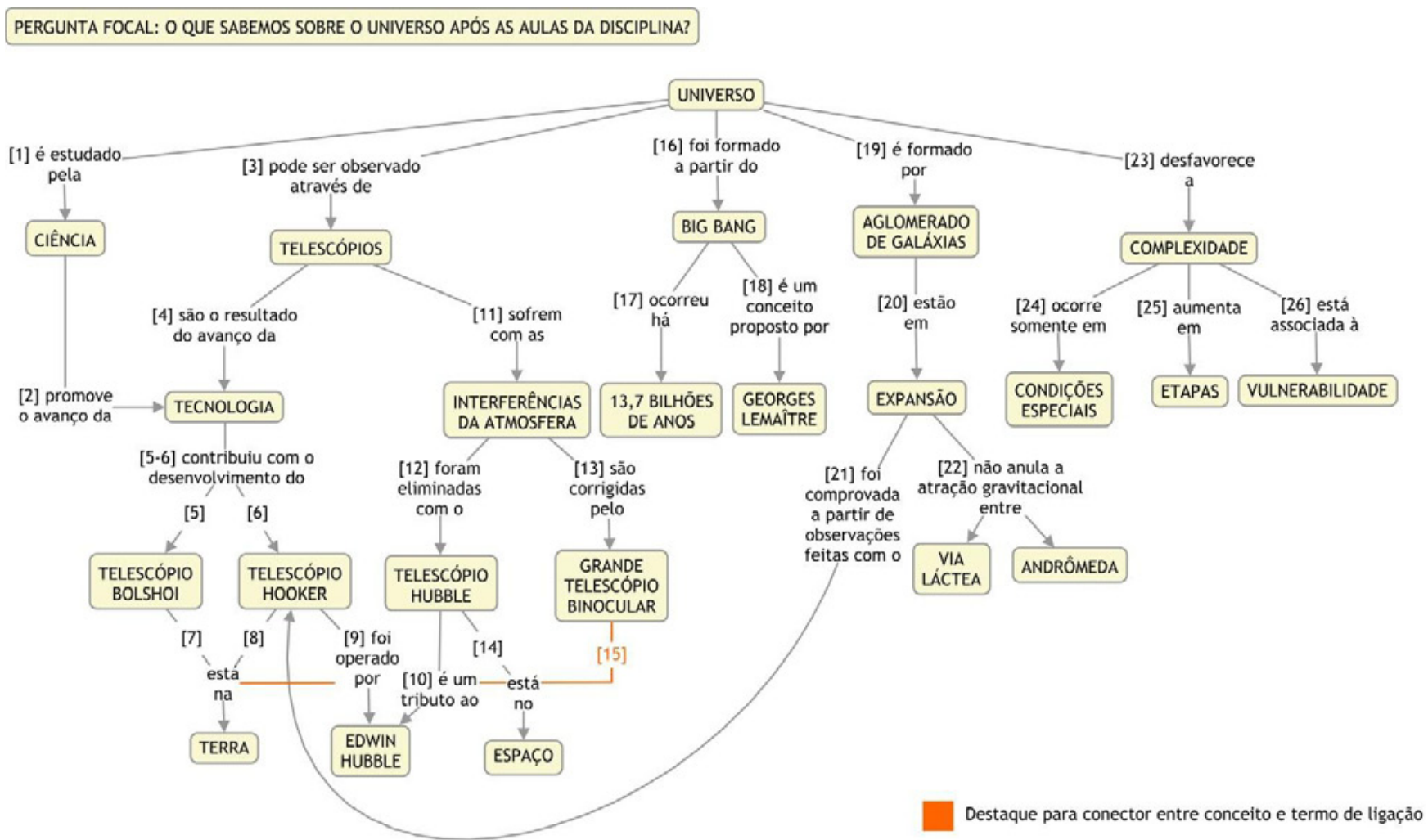

Figura 1 - Mapa conceitual elaborado pelo professor para visualizar de forma sistêmica os conteúdos trabalhados durante quatro aulas da disciplina ACH 0131, Giências da Natureza: Ciência, Cultura e Sociedade, oferecida no Ciclo Básico da EACH/USP. 
- avaliar a adequação dos materiais de estudo escolhidos, bem como definir a melhor organização sequencial dos conteúdos ao longo das aulas.

Esse mapa pode ser levado à sala de aula e apresentado aos alunos, numa atividade de fechamento desse bloco temático. $\mathrm{O}$ professor pode projetar o mapa e discutir as relações conceituais para sistematizar o conteúdo das aulas (CORREIA, 2012). Outra possibilidade é desenvolver um organizador prévio, a ser utilizado logo no início de uma sequência de aulas. Nesse caso, o objetivo é preparar os alunos para os conteúdos que serão apresentados, destacando os conceitos mais centrais e abrangentes que sustentam as discussões subsequentes (CUTRER et al., 2011; GURLITT et al., 2012; MOREIRA, 2008; WILLERMAN \& HARG, 1991). Em outras palavras, o professor cria um "plano de voo" geral para o bloco temático, sem detalhar o que será visto em cada uma delas. O uso de organizadores prévios foi proposto por Ausubel para gerar uma ponte cognitiva entre os novos conhecimentos e os conhecimentos prévios, já existentes na estrutura cognitiva dos alunos (AUSUBEL, 2000; MOREIRA, 2008). O professor pode utilizar o mapa da Figura 1 como ponto de partida para a criação de um organizador prévio (Figura 2), que apresenta somente os conceitos mais centrais e abrangentes sobre o conteúdo.

\section{Mapa Conceitual Parcialmente Desenvolvido}

Atividades de elaboração de mapas conceituais pelos alunos podem ser subsidiadas por estruturas parcialmente desenvolvidas, como a apresentada na Figura 3. Esse mapa foi criado a partir de uma simplificação do mapa do professor (Figura 1), e sua rede proposicional contém doze conceitos e onze proposições. Os conceitos retirados ( $\mathrm{n}=$ 11) formam um banco que pode (ou não) ser disponibilizado aos alunos. As atividades a serem desenvolvidas a partir desse mapa conceitual podem valorizar:

- cada aluno trabalhando individualmente na expansão da rede proposicional,

- a formação de pequenos grupos para estimular as discussões entre os alunos, e

- a participação do professor mediando a construção do mapa conceitual com a turma toda.

O mapa conceitual parcialmente desenvolvido facilita a participação dos alunos como mapeadores, porque ele fornece um ponto de partida para a inclusão de novos conceitos que orienta a atividade. Ela é mais simples do que construir um mapa por completo, a partir de uma folha em branco. Além disso, a mediação do professor pode ser feita durante a aula para que as contribuições apresentadas pelos alunos se aproximem das relações conceitualmente corretas. Esses aspectos reduzem a necessidade de treinar os alunos na técnica de mapeamento conceitual. Quando o

PERGUNTA FOCAL: O QUE VAMOS APRENDER SOBRE O UNIVERSO NAS PRÓXIMAS AULAS DA DISCIPLINA?

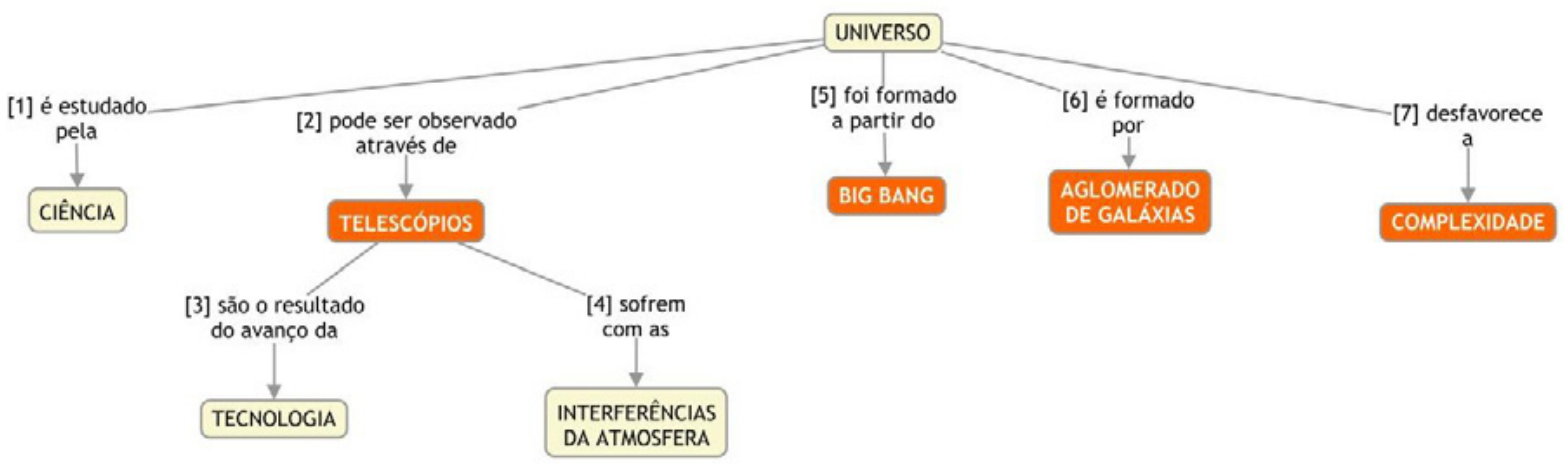

Conceitos centrais e mais abrangentes sobre o conteúdo

Figura 2 - Exemplo de organizador prévio na forma de mapa conceitual, desenvolvido a partir do mapa do professor (Figura 1). Várias proposições foram removidas, e a pergunta focal foi modificada. 


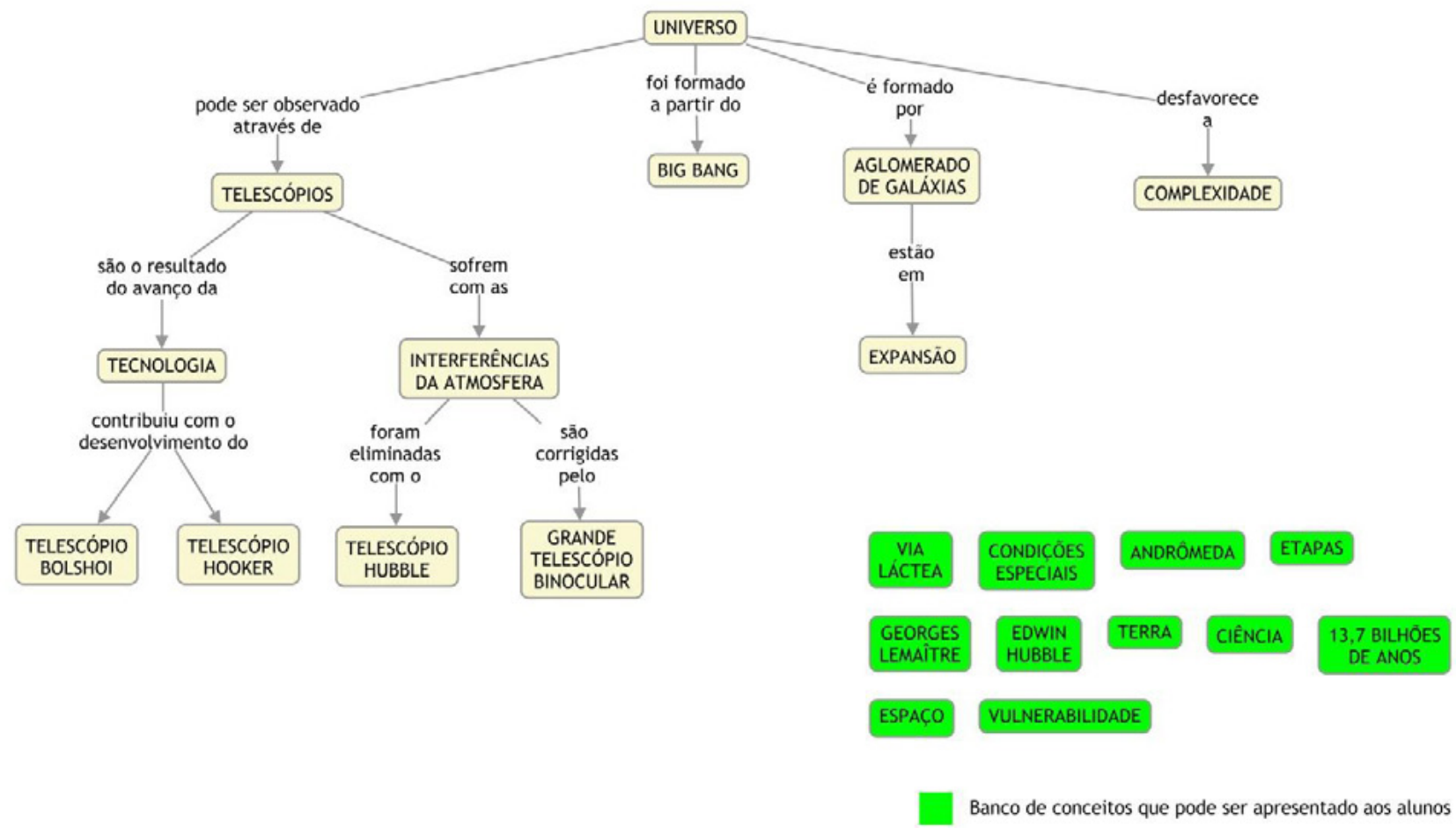

Figura 3 - Mapa conceitual parcialmente desenvolvido a ser utilizado em atividades elaborativas na sala de aula. O banco de conceitos pode (ou não) ser oferecido, dependendo dos objetivos a serem atingidos pelo professor.

treinamento for indispensável, o professor pode explorar as atividades baseadas nos mapas parcialmente desenvolvidos como um dos exercícios a serem apresentados aos iniciantes.

\section{Relações entre as Proposições e os Materiais de Estudo}

A articulação entre diferentes materiais de estudo pode ser importante para a compreensão dos conteúdos trabalhados em aula. Nesse caso, os alunos devem explorar textos, vídeos, exercícios e o que mais foi oferecido pelo professor para chegar a uma síntese que vincule os conceitos num quadro coerente. Uma forma rápida de verificar o engajamento dos alunos com os materiais de estudo é a partir do mapa do professor (Figura 1), que conhece a priori a fonte das relações conceituais incluídas na rede proposicional. A atividade proposta aos alunos consiste na identificação dos materiais de estudo que originaram os conceitos $(\mathrm{n}=23)$ e as proposições $(\mathrm{n}=26)$ do mapa, utilizando cores específicas para representar cada material de interesse. As respostas dos alunos podem ser rapidamente comparadas com o mapa da Figura 4, organizado em cores que indicam os vídeos e o texto que foram utilizados nas aulas sobre o universo. $\mathrm{O}$ professor pode avaliar se há algum material que não foi devidamente explorado pelos alunos para, em seguida, alertá-los sobre a necessidade de estudá-lo.

Nossa experiência com essa atividade mostrou que os alunos da disciplina fizeram uma boa identificação dos conceitos relacionados com o documentário Gigantes da Engenharia: Telescópios (amarelo) e com o texto "O Ovo Cósmico" (laranja). O professor teve indícios de que os conteúdos desses materiais foram adequadamente trabalhados. Por outro lado, os conceitos referentes ao vídeo $A$ História do Universo em 18 Minutos (verde) não foram relacionados com esse material pela maioria dos alunos. Esse padrão destoante foi explicado pelo professor, que havia recomendado esse vídeo como tarefa extraclasse. As evidências obtidas com essa atividade revelaram que poucos alunos assistiram ao vídeo, apesar da solicitação do professor. A identificação dos materiais de estudo se mostrou uma atividade rápida (aproximadamente vinte minutos), que pôde ser desenvolvida 


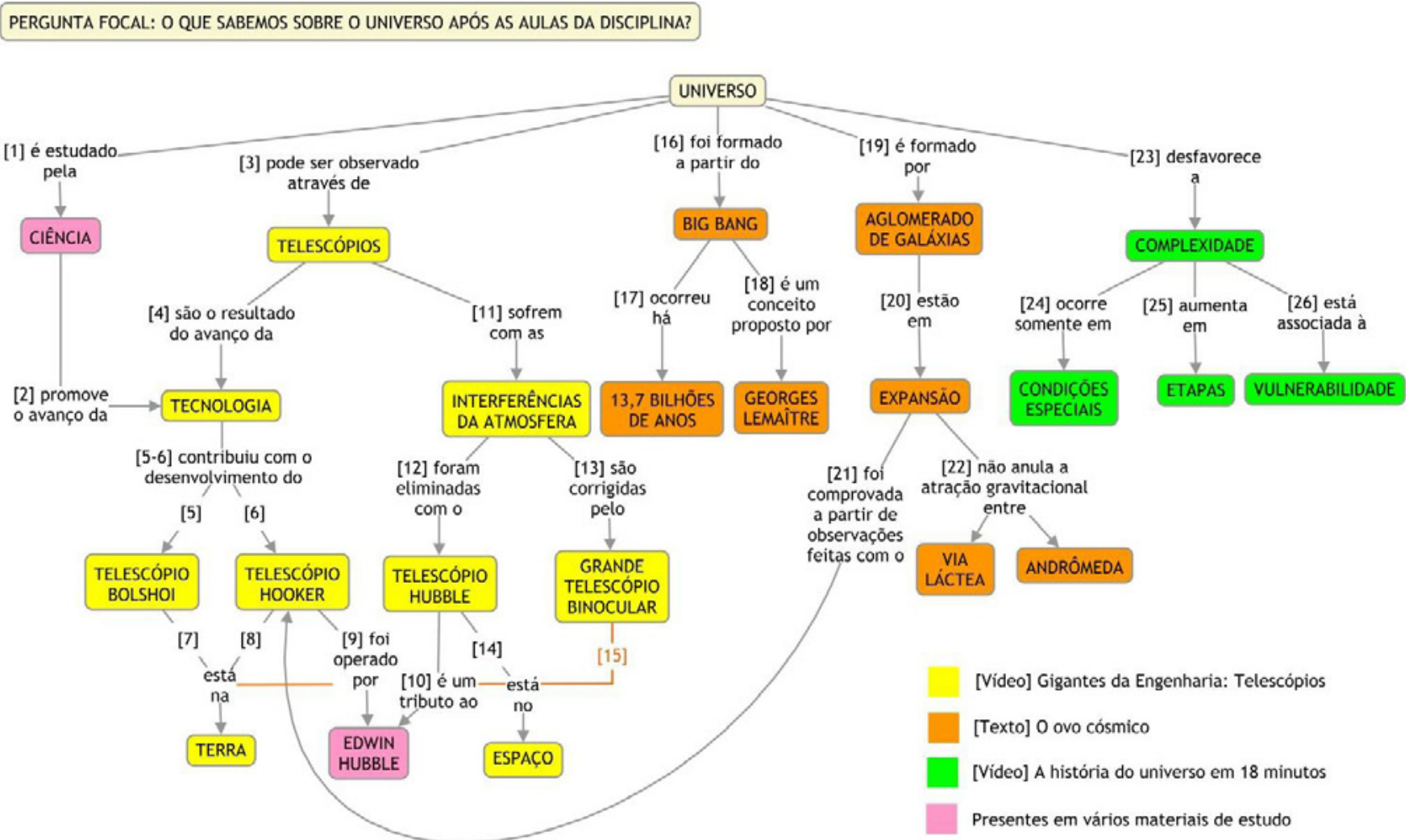

Figura 4 - Mapa conceitual elaborado pelo professor para relacionar o conteúdo mapeado com os materiais de estudo utilizados na disciplina. Essa atividade permite verificar se os alunos trabalharam adequadamente com todos os materiais.

pelos alunos de forma individual e em pequenos grupos, capaz de gerar informações precisas para que o professor avaliasse o engajamento dos alunos com os materiais da disciplina.

\section{Identificação dos Erros no Mapa Conceitual}

A identificação de erros conceituais só é possível quando se compreende o tema estudado. Esse é o pressuposto que norteia a atividade baseada no mapa conceitual com erros. O professor pode editar o seu mapa conceitual (Figura 1), alterando alguns termos de ligação para criar proposições inválidas, considerando-se os conteúdos estudados. Os conceitos mais relevantes para o entendimento do tema são bons candidatos a receberem tais erros. Nosso grupo de pesquisa é pioneiro no desenvolvimento desse tipo de atividade, que já foi apresentada na conferência internacional sobre mapas conceituais (CORREIA, CABRAL \& AGUIAR, 2016). A Figura 5 apresenta o mapa conceitual do professor com as edições destacadas em laranja. Das 26 proposições do mapa, 9 estão incorretas (P1, P10, P12, P13, P15, P17, P18, P22 e P23).

Os mapas com erro apresentam quatro vantagens que viabilizam a sua utilização nas condições usuais de trabalho do professor:

1. a facilidade de criar várias atividades a partir do mesmo mapa, variando a quantidade e a localização dos erros (Tabela 3),

2. o tempo reduzido (aproximadamente quinze minutos) para que os alunos leiam o mapa e identifiquem a localização dos erros através da numeração das proposições,

3. a rapidez no processo de correção da atividade, que pode ser feita pelo professor em sala de aula (ele informa onde estão os erros do mapa), e

4. a produção de uma devolutiva imediata e personalizada para os alunos, caso o professor informe o que deve ser reestudado a partir dos erros não identificados.

A possibilidade de formular uma devolutiva rápida e personalizada deve ser valorizada, pois ela favorece a ressonância pedagógica, definida 


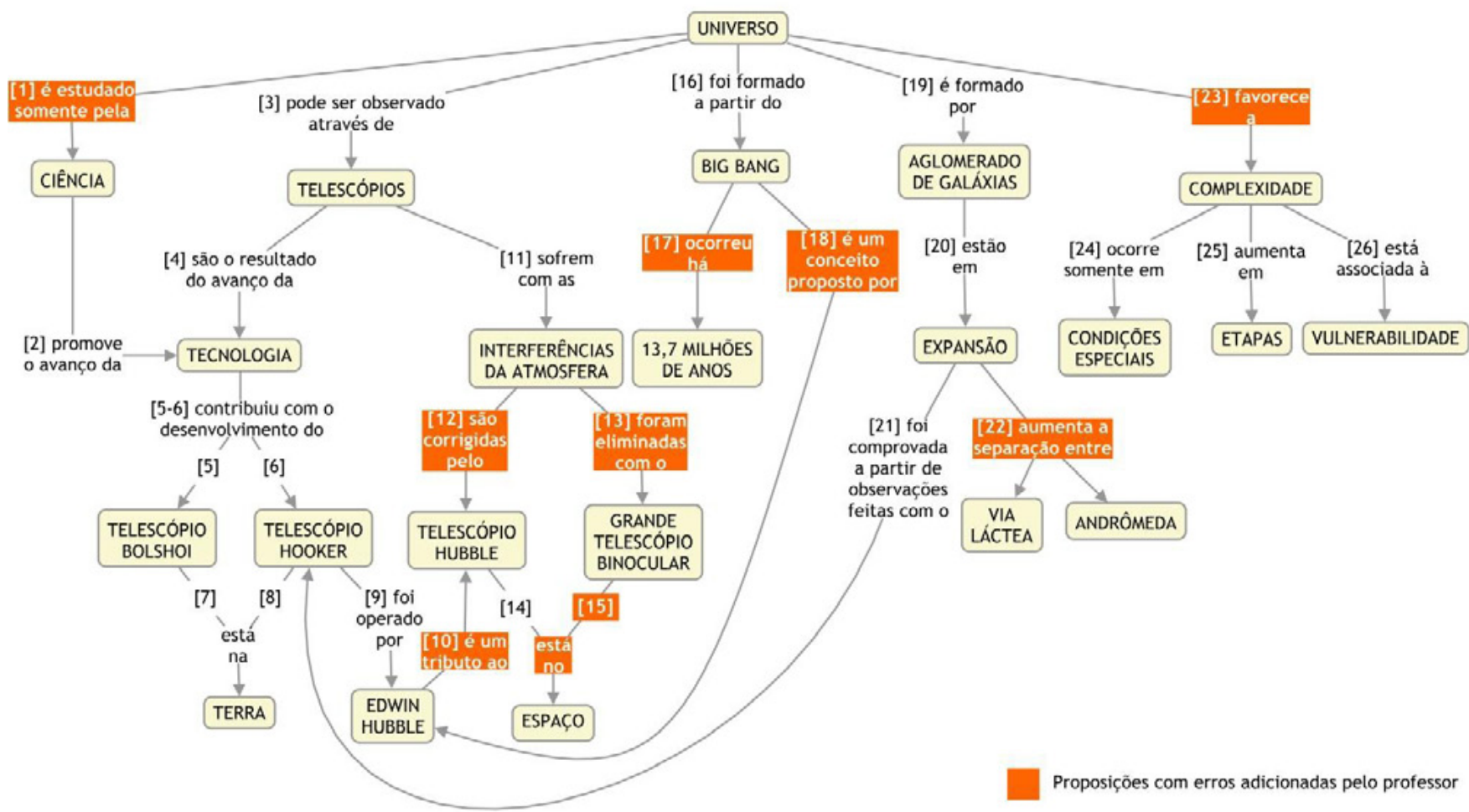

Figura 5 - Mapa conceitual do professor (Figura 1), editado por ele para a inclusão de proposições inválidas ( $\mathrm{n}=$ 9). Os alunos recebem um mapa sem destaques coloridos para identificar a localização dos erros.

\begin{tabular}{|l|l|l|l|l|l|l|l|l|l|}
\hline \multicolumn{1}{|l|}{ Proposições com erros } \\
\hline Versão & {$[1]$} & {$[10]$} & {$[12]$} & {$[13]$} & {$[15]$} & {$[17]$} & {$[18]$} & {$[22]$} & {$[23]$} \\
\hline A (9 erros) & $X$ & $X$ & $X$ & $X$ & $X$ & $X$ & $X$ & $X$ & $X$ \\
\hline B (6 erros) & $X$ & - & $X$ & $X$ & - & - & $X$ & $X$ & $X$ \\
\hline C (5 erros) & $X$ & $X$ & - & - & $X$ & $X$ & - & $X$ & - \\
\hline
\end{tabular}

Tabela 3 - Sugestão de três versões diferentes de atividades baseadas nos mapas com erros, a partir do mapa conceitual da Figura 5 (versão A). Os erros a serem incluídos em cada versão foram indicados com "X".

como "a ponte entre o conhecimento do professor e a aprendizagem do aluno" (KINCHIN, LYGOBAKER \& HAY, 2008). Nesse caso, a opção pela aprendizagem profunda, em detrimento da aprendizagem superficial, é estimulada durante todas as aulas da disciplina (CORREIA et al., 2016).

\section{Conclusão}

Apesar de serem desejáveis, as atividades baseadas nos mapas elaborados pelos alunos apresentam desafios de ordem prática que são incompatíveis com a rotina profissional da maioria dos professores. Isso dificulta a utilização do mapeamento conceitual como uma prática frequente, impedindo a verificação dos benefícios descritos na literatura. Uma forma de lidar com essa situação é colocar o professor na condição de mapeador. Ele deve fazer seus próprios mapas conceituais e, a partir deles, planejar atividades como as que foram descritas neste artigo. $\mathrm{O}$ tempo de execução da atividade e o processo de correção ficam mais rápidos e compatíveis com a dinâmica das aulas. Além disso, as devolutivas imediatas e personalizadas podem ser formuladas pelo professor, facilitando 
o estabelecimento da ressonância pedagógica. Por fim, cabe destacar que várias atividades podem ser desenvolvidas a partir de um único mapa conceitual feito pelo professor, conforme foi apresentado nas Figuras 1 a 5.

\section{Agradecimentos}

Nosso grupo de pesquisa agradece ao $\mathrm{CNPq}$ (440686/2014-8) e à Fapesp (2016/24553-7) o apoio financeiro. Raíssa dos Santos Ballego e Thalita de Souza Nascimento agradecem as bolsas de iniciação científica concedidas pela Universidade de São Paulo, no âmbito do Programa Unificado de Bolsas (Editais PUB 2016/2017 e PUB 2017/2018). Raíssa dos Santos Ballego e Thalita de Souza Nascimento agradecem à Capes as bolsas de mestrado.

\section{Referências Bibliográficas}

AGUIAR, Joana G. \& CORREIA, P. R. M. "Como Fazer Bons Mapas Conceituais? Estabelecendo Parâmetros de Referências e Propondo Atividades de Treinamento". Revista Brasileira de Pesquisa em Educação em Ciências, vol. 13, n. 2, 2013, pp. 141-157. Disponível em: <https:// seer.ufmg.br/index.php/rbpec/article/view/2469>. Acessado em 3 set. 2018.

AUSUBEL, D. P. The Acquisition and Retention of Knowledge: A Cognitive View. Dordrecht: Kluwer Academic Press, 2000.

COOPER-CAPETINI, Vinícius; PEREIRA, A. G.; LINS, B. B.; SILVA-JUNIOR, J. S.; ASSIS, L. V. M.; BELPIEDE, L. T.; COSTA, M. R. J.; NUNES, P. P.; CASTELO-BRANCO, R. C. \& NUNES, M. T. "A Utilização de Vídeos no Ensino: uma Experiência Prática com Alunos de Graduação". Revista de Graduação da USP, vol. 2, n. 2, 2017, pp. 107-113. Disponível em: <https:// doi.org/10.11606/issn.2525-376X.v2i2p107-113>. Acessado em 3 set. 2018.

CONGEIÇÃO, Simone G. O.; SAMUEL, A. \& BINIECKI, S. M. Y. "Using Concept Mapping as a Tool for Conducting Research: An Analysis of Three Approaches". Cogent Social Sciences, vol. 3, n. 1, 2017, 1404753. Disponível em: <https://doi. org/10.1080/23311886.2017.1404753>. Acessado em 3 set. 2018.

CORREIA, Paulo R. M. "The Use of Concept Maps for Knowledge Management: from Classrooms to Research Labs". Analytical and Bioanalytical Chemistry, vol. 402, n. 6, 2012, pp. 1979-1986. Disponível em: 〈https://doi.org/10.1007/s00216-011-5694-8>. Acessado em 3 set. 2018.

CORREIA, Paulo R. M.; AGUIAR, J. G.; VIANA, A. D. \& CABRAL, G. G. P. "Por que Vale a Pena Usar Mapas Conceituais no Ensino Superior?". Revista de Graduação da USP, vol. 1, n. 1, 2016, pp. 41-51. Disponível em: <https:// doi.org/10.11606/issn.2525-376X.v1i1p41-51>. Acessado em 3 set. 2018.

CORREIA, Paulo R. M.; CABRAL, G. C. P. \& AGUIAR, J. G. "Cmaps with Error: why not? Comparing two Cmap-Based Assessment Tasks to Evaluate Conceptual Understanding". In: CAÑAS, A.; REISKA, P. \& NOVAK, J. (Eds.). Innovating with Concept Mapping. CMC 2016. Communications in Computer and Information Science, vol. 635, 2016, pp. 1-15. Cham: Springer. Disponível em: <https://doi.org/10.1007/978-3319-45501-3_1>. Acessado em 3 set. 2018.

GUTRER, William B.; CASTRO, D.; ROY, K. M. \& TURNER, T. L. "Use of an Expert Concept Map as an Advance Organizer to Improve Understanding of Respiratory Failure". Medical Teacher, vol. 33, n. 12, 2011, pp. 10181026. Disponível em: $>$ https://doi.org/10.3109/01 42159X.2010.531159>. Acessado em 3 set. 2018.

DIAS, Sylmara L. F. G.; SCÓTOLO, D.; AGUIRRA, I.; SILVA, G. T. \& LIMA, B. A. A. "Uso dos Mapas Conceituais na Dinâmica da Sala de Aula: Relato de Experiência na Disciplina Sociedade, Meio Ambiente e Cidadania (EACHUSP)". Revista de Graduação da USP, vol. 2, n. 3, 2017, pp. 187-192. Disponível em: <https://doi. org/10.11606/issn.2525-376X.v2i3p187-192>. Acessado em 3 set. 2018.

GURLITT, Johannes; DUMMEL, S.; SGHUSTER, S. \& NÜGKLES, M. "Differently Structured Advance Organizers Lead to Different Initial Schemata and Learning Outcomes". Instructional Science, vol. 40, n. 2, 2012, pp. 351-369. 
Disponível em: <https://doi.org/10.1007/s11251011-9180-7>. Acessado em 3 set. 2018.

KINCHIN, Ian M.; STREATFIELD, M. A. \& HAY, D. B. "Using Concept Mapping to Enhance the Research Interview". International Journal of Qualitative Methods, vol. 9, n. 1, 2010, pp. 52-68. Disponível em: <https://doi.org/10.1177/1609406 91000900106>. Acessado em 3 set. 2018.

KINCHIN, Ian M.; LYGO-BAKER, S. \& HAY, D. B. "Universities as Centres of NonLearning". Studies in Higher Education, vol. 33, n. 1, 2008, pp. 89-103. Disponível em: <https://doi. org/10.1080/03075070701794858>. Acessado em 3 set. 2018.

McCLURE,JohnR.;SONAK, B.\&SUEN,H.K. "Concept Map Assessment of Classroom Learning: Reliability, Validity, and LogisticalPracticality". Journal of Research in Science Teaching, vol. 36, n. 4, 1999, pp. 475-492. Disponível em: <https://doi.org/10.1002/ (SICI) 1098-2736(199904)36:4<475::AIDTEA5>3.0.CO;2-O > . Acessado em 3 set 2018.

MELO, Celso E. S. "Metodologias Ativas de Ensino e Aprendizagem no Curso de Direito: Breves Relatos de Experiência na Faculdade Ages". Revista de Graduação da USP, vol. 3, n. 2, 2018, pp. 107-112. Disponível em: <https://doi. org/10.11606/issn.2525-376X.v3i2p107-112>. Acessado em 3 set. 2018.

MOREIRA, Marco A. "Organizadores Previos y Aprendizaje Significativo". Revista Chilena de Educacion Científica, vol. 7, n. 2, 2008, pp. 23-30. Versão em português disponível em: $<$ https://www. if.ufrgs.br/ moreira/ORGANIZADORESport. pdf $>$. Acessado em 3 set 2018.

MOREIRA, Marco A. Mapas Conceituais e Aprendizagem Significativa. São Paulo: Centauro, 2010.
NOVAK, Joseph D. Learning, Creating and Using Knowledge: Concept Maps as Facilitative Tools in Schools and Corporations. 2a ed. New York, NY: Routledge, 2010.

NOVAK, Joseph D. \& CAÑAS, A. J. "The Universality and Ubiquitousness of Concept Maps". In: Proceedings of the Fourth International Conference on Concept Mapping. Viña del Mar: Universidad de Chile, 2010, pp. 1-10. Disponível em: <http://cmc.ihmc.us/cmc2010papers/cmc2010-p1.pdf>. Acessado em 3 set. 2018.

RIBEIRO, Roberto P. \& VIANA, A. B. N. "Estruturação do PBL para Aplicação em Disciplinas do Gurso de Graduação em Administração". Revista de Graduação da USP, vol. 3, n. 1, 2018, pp. 39-47. Disponível em: 〈https:// doi.org/10.11606/issn.2525-376X.v3i1p39-47>. Acessado em 3 set. 2018.

SCHWENDIMANN, Beat A. "Concept Maps as Versatile Tools to Integrate Complex Ideas: from Kindergarten to Higher and Professional Education". Knowledge Management \& E-Learning, vol. 7, n. 1, 2015, pp. 73-99.

SILVA JUNIOR, Carlos A. P. \& FONTENELE, H. B. \& SILVA, A. N. R. "Mapas Conceituais para Avaliação do EnsinoAprendizagem em uma Disciplina de Engenharia de Transportes". Revista de Graduação da USP, vol. 2, n. 2, 2017, pp. 23-30. Disponível em: 〈https:// doi.org/10.11606/issn.2525-376X.v2i2p23-30>. Acessado em 3 set. 2018.

WILLERMAN, Marvin \& HARG, R. A. M. "The Concept Map as an Advance Organizer". Journal of Research in Science Teaching, vol. 28, n. 8, 1991, pp. 705-711. Disponível em: <https://doi. org/10.1002/tea.3660280807>. Acessado em 3 set. 2018

Publicado em 28/07/2020. 